\title{
Prediction and Optimization of Internal Return Fines Generation in Iron Ore Sintering Using Machine Learning
}

\author{
Srijith Mohanan ${ }^{1, ~ *, ~ P r a j n a ~ M o h a p a t r a ~}{ }^{1}$, Arun Kumar C. ${ }^{2}$, Rama Krishna Adepu ${ }^{1}$, \\ Vipul Mohan Koranne', Y. G. S. Prasad ${ }^{1}$, A. S. Reddy ${ }^{2}$, R. V. Ramna ${ }^{2}$ \\ ${ }^{1}$ Tata Steel Kalinganagar, Duburi, India \\ ${ }^{2}$ Tata Steel Jamshedpur, Jamshedpur, India
}

\section{Email address:}

srijith.mohanan@tatasteel.com (S. Mohanan), prajna.m@tatasteel.com (P. Mohapatra), arunkumar.c@tatasteel.com (Arun K. C.), rk.adepu@tatasteel.com (R. K. \depu), vipulmohankoranne@tatasteel.com (V. M. Koranne), ygs.prasad@tatasteel.com (Y. G. S. Prasad), asreddy@tatasteel.com (A. S. Reddy),rvramna@tatasteel.com (R. V. Ramna)

*Corresponding author

\section{To cite this article:}

Srijith Mohanan, Prajna Mohapatra, Arun Kumar C., Rama Krishna Adepu, Vipul Mohan Koranne, Y. G. S. Prasad, A. S. Reddy, R. V. Ramna. Prediction and Optimization of Internal Return Fines Generation in Iron Ore Sintering Using Machine Learning. Advances in Materials. Vol. 10, No. 3, 2021, pp. 42-47. doi: 10.11648/j.am.20211003.12

Received: August 3, 2021; Accepted: August 13, 2021; Published: October 28, 2021

\begin{abstract}
Prior to dispatch of sinter to the blast furnace for hot metal production, the sinter product from the sinter cooler is screened to remove smaller/finer particles. The undersize so generated is called internal return fines, which are generally recirculated into the sintering machine. A very high level of internal return fines generation limits the use of virgin ore for sintering which may hamper sinter productivity. Recently, the sinter plant at Tata Steel's Kalinganagar works has faced issues of high internal return fines generation. As the sinter plant begins to increase its productivity levels, it becomes critical to control the generation of internal return fines to allow fresh material consumption. Limited literature is available on factors affecting the internal return fines generation in sinter plant. Given the current computational capabilities, a machine learning model was developed to ascertain the factors affecting the internal return fines generation. The development of the machine learning model and the optimization carried out based on model output is described in this work. The key parameters affecting the internal return fines generation were the sintering rate, sinter basicity, charge density and temperature in the ignition hood. In Kalinganagar, the increase in ignition hood temperature was limited by the furnace refractory condition. Further, the sinter basicity is determined by the percentage of sinter in blast furnace burden. Incorporating these constraints, the model was used to optimize the process parameters to generate the lowest possible return fines. The understanding generated from this machine learning framework has resulted in a reduction of $2-3 \%$ in internal return fines generation, which implied higher net sinter production.
\end{abstract}

Keywords: Machine Learning, Internal Return Fines, Sintering Rate, Prediction

\section{Introduction}

Sintering process is the most widespread method to agglomerate iron ore fines in the Indian steel industry. At Tata Steel's Kalinganagar (TSK) works, sinter is the major agglomerate in the blast furnace burden. During the sintering process, a mix of iron ores fines, fluxes and solid fuel (coke breeze), previously homogenized and pelletized, are discharged onto a moving strand and leveled to form a homogeneous bed. An ignition furnace starts combustion of the upper layers at the beginning of the strand. A large fan sucks air down through the bed through the wind boxes equipped with thermocouples that measure the temperature of the sucked gas. The sinter product is formed along the strand through the physical and chemical processes occurring within the bed. Combustion of coke breeze takes place in a flame front which migrates across the bed. This flame front should reach the grate of the machine at a certain distance before the strand ends, since the cooling stage should begin in the last part of the strand [1]. Finally, the sinter is cooled in a rotary cooler using forced 
convection through an upward flow of ambient air. After being discharged, the material is classified by a screen (generally 5 or $6 \mathrm{~mm}$ ) and products of acceptable size are carried to the blast furnace by means of several conveyor belts. The smaller pieces of product are returned to be reprocessed. This undersize product stream is usually called internal return fines (IRF). When demand for sinter exceeds the production capability of sinter plant, it becomes imperative to reduce both internal and external (generated while screening at blast furnace) return fines.

There is significant amount of literature available on factors that affect the generation of return fines at the blast furnace end. Jan et al [2] had studied the impact of return sinter fines from the blast furnace on the sintering process and its impact on productivity by varying the quantity of return fines in base mix. Bhagat et al [3] further studied the impact of Indian iron ores and sinter chemistry on external fines generation and its impact on recirculation in sinter plant. Use of machine learning to improve sintering process has been carried out in the past mostly with respect to sinter $\mathrm{FeO}$ prediction [4] and controlling quality of sinter based on development of quality indices [5].

Very limited literature is available on enablers to increase gross sinter and to generate lower internal return fines at sinter plant. The most common control philosophy is to control the ignition of the upper layers of the strand using expert loop systems, since the weakest sinter is generated in the top layers [6, 7]. The present study gains significance because the internal return fines (expressed henceforth as a percentage of base mix) generation was on the higher side at Tata Steel's Kalinganagar works ( 26-28\%).

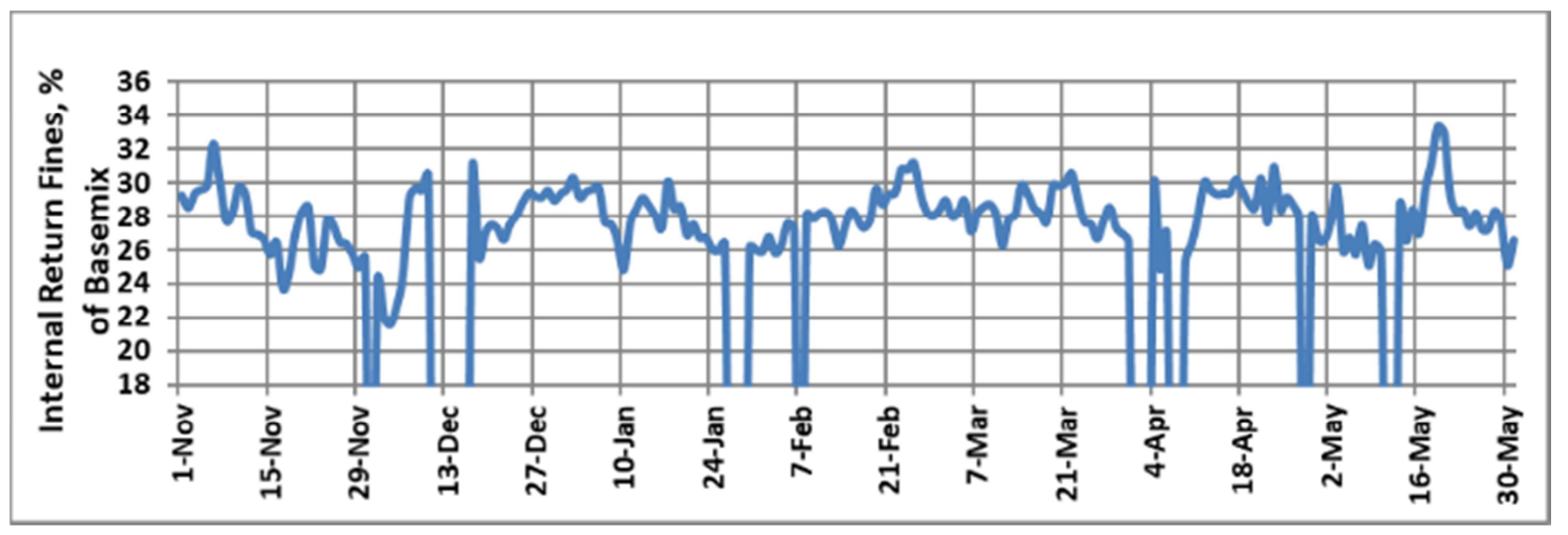

Figure 1. Trend of internal return fines, TSK SP, $1^{\text {st }}$ Nov 2018-31 $1^{\text {st }}$ May 2019.

The trend shows certain spells where the internal return fines are low and other spells where it has been high. In the present work, an attempt is made to using advanced analytical tools such as Machine Learning algorithms on a sufficiently large data set to determine the levers that enable lower internal return fines generation. Machine learning is a subset of artificial intelligence that uses advanced computational algorithms to observe patterns in data sets and evolve prediction based on experience. Recent advances in computational technology coupled with large availability of measured data have helped to provide a strong foundation for process optimization using such tools. Machine learning has also been used elsewhere in the steel plant where there is limited knowledge and literature available regarding factors impacting the target parameter [8].

In recent years, there have been a number of recent literature is available that quantify the impact of iron ore fines quality on the sintering process [9, 10]. Further the impact of mineralogical composition of these ores and the impact of alumina from ores of Indian origin on sinter quality have also been studied [11-13]. The process control required to achieve desired sinter properties is also specified. Most of these works relate to reduction in external return fines from the blast furnace. There is limited literature available regarding their impact on internal return fines generation.

\section{Methodology and Model Development}

The sintering process involves a series of steps - handling of iron ore fines, blend preparation with prerequisite fluxes and solid fuel based on required sinter properties and target chemistry, reclaiming of blended material, control of granulation, control of sintering process and cooling - to obtain quality sinter as desired by blast furnaces. The return fines generated within the sinter plant is a result of several interacting parameters in these unit operations. With recent advances in computational and modelling capability, it is possible to ascertain these interactions and identify key enablers that would enable control of a resultant parameter in this case, the internal return fines generation. A brief description of the modeling tools used in the present analysis are as below:

a. Linear Multivariate Regression: As the name implies, multivariate regression is a technique that estimates a single regression model with more than one outcome variable. When there is more than one predictor variable in a multivariate regression model, the model is a multivariate multiple regression.

b. Random Forest: Random forest algorithm is a supervised classification and regression algorithm. This 
algorithm randomly creates a forest with several trees. The higher the number of trees in the forest, greater is the accuracy of the results. In simple words, Random forest builds multiple decision trees (called the forest) and glues them together to get a more accurate and stable prediction. The forest it builds is a collection of Decision Trees, trained with the bagging method.

c. Boosted Regression with Stacking: In contrast to random forest which is a bagging method, in boosted regression one uses very simple classifiers as base classifiers, so-called "weak learners." Here, we start with one decision tree stump and "focus" on the samples it got wrong. In the next round, we train another decision tree stump that attempts to get these samples right; we achieve this by putting a larger weight on these training samples. This method is continued till the best fit is achieved.

For the present analysis, data set consisting of 26 input parameters mentioned in table 1 below are considered for the period from April 2018 to July 2019. The parameters are classified into pile, process and output parameters. Some parameters are further derived from the above set - these are classified as calculated parameters and are commonly used in the sintering process.

Table 1. Input parameters to Machine Learning model.

\begin{tabular}{ll}
\hline Pile Parameters & Percentage of individual ores in pile (A, B, C, D), Percentage of revert material used, Crushing fineness of solid fuel and \\
& fluxes $(-3.15 \mathrm{~mm}, \%)$, solid fuel rate \\
Process Parameters & Machine Speed, Bed Height, Ignition Hood temperature, Burn Through Temperature, Combustion air inlet temperature, Burn \\
& Through Point length, Waste Gas temperature, Suction, Discharge end temperature \\
Calculated Parameters & Flame Front Speed, On strand cooling, Japanese Permeability Unit (JPU), Green Mix Permeability, Charge Density \\
Sinter Chemistry & $\mathrm{Al}_{2} \mathrm{O}_{3}, \mathrm{MgO}, \mathrm{FeO}$, sinter basicity $\left(\mathrm{CaO} / \mathrm{SiO}_{2}\right)$ \\
\hline
\end{tabular}

The data are collected on an hourly basis cleaned for outliers and the three different techniques mentioned above are used to predict the internal return fines. The data are split into training set and testing set in the ratio of 70:30. The key results of the analysis are as shown below in Table 2. In the below table, RMSE refers to Root Mean Square Error, which is used here as an indicator of good model fit. The lower the RMSE, the closer the prediction is to the actual value of the estimate.

Table 2. Model Output Results.

\begin{tabular}{llll}
\hline Model Type & Linear Multivariate Regression & Random Forest & Boosted with Stacking \\
\hline RMSE - training set & 1.95 & 1.58 & 1.48 \\
RMSE - testing set & & 1.63 & 1.7 \\
Delta RMSE & $47 \%$ & 0.05 & 0.08 \\
Correlation - training set & & $65 \%$ & $73 \%$ \\
Correlation - testing set & & $64 \%$ & $40 \%$ \\
\hline
\end{tabular}

Of the above techniques, the random forest model is chosen based on the lower difference in correlation between the training set and testing set. The sample prediction is shown in figure 2 below. The model can predict the directionality and is quite close to the actual values, except at those points where the actual return fines generation is quite low, below $22 \%$. Number of such data points is quite less and further online training of the model could provide a better prediction.

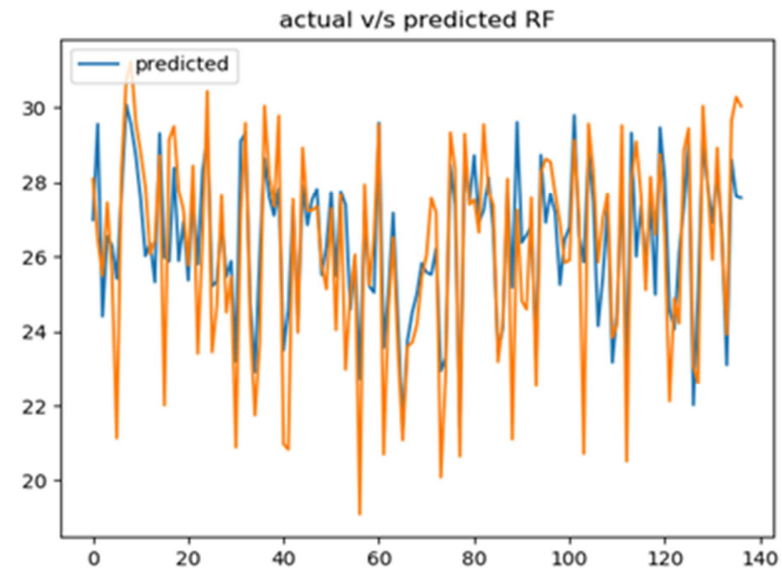

Figure 2. Prediction (blue) vs Actual (orange) - Random Forest Model for Internal Return Fines Generation.

\section{Results and Discussion}

\subsection{Permutation Feature Importance}

To ascertain the key factors impacting internal return fines generation, a permutation feature importance study was carried out. The study allows to identify key parameters that affect the internal return fines generations and rank them in order of their importance. This allows the operator to identify levers to control the process. The results are shown in table 3. It is clear from the table below that the internal return fines generation is impacted by the rate of sintering (Suction, burn through length, flame front speed), characteristics of the bonding phases (sinter basicity) and packing of the green mix on the sinter bed (charge density).

Table 3. Key Factors Impacting Internal Return Fines Generation.

\begin{tabular}{lll}
\hline Feature Ranking & Parameter & Type \\
\hline 1 & Burn through length & Process \\
2 & Suction & Process \\
3 & Sinter Basicity & Product Chemistry \\
4 & Charge Density & Process \\
5 & Flame Front Speed & Process \\
6 & Ignition Hood Temperature & Process \\
7 & Percentage of Ore D in pile & Pile \\
8 & Percentage of Ore A in pile & Pile \\
\hline
\end{tabular}




\subsection{Effect of Sinter Basicity}

Of the quality factors, sinter basicity is found to have a significant impact on the internal return fines generation. The impact of sinter basicity is shown in figure 3 below, with internal return fines as percentage of base mix. Increasing sinter basicity results in lower internal fines generation, which is primarily due to formation of stronger bonding phases of silico ferrite of calcium and aluminum (SFCA) in sinter [14]. However, the basicity of sinter is determined by the percentage of sinter in the blast furnace burden. Since, sinter is the major component in blast furnace metallic burden at Tata Steel Kalinganagar (75-78\%), sinter basicity is kept on lower side to control slag rate. Thus, there is limited scope to further vary the sinter basicity to optimize internal return fines in actual plant operations.

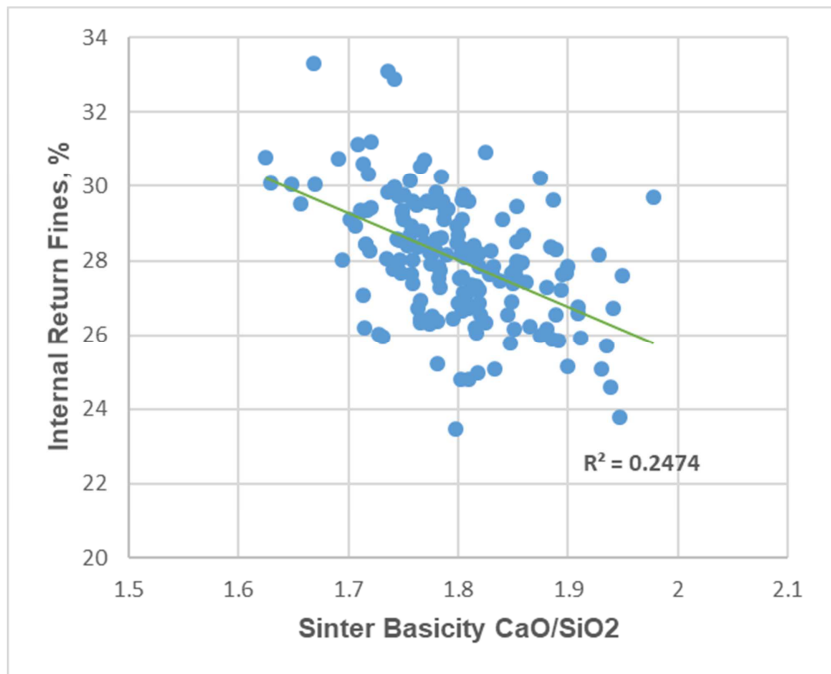

Figure 3. Impact of sinter basicity.

\subsection{Effect of Charge Density}

The charge density, calculated from the green mix charging rate, machine speed and bed height (1) is to be operated at an optimized value to obtain good permeability. Higher charge density leads to increased resistance to gas flow, while a loosely packed bed can result in lower heat utilization in the sinter bed. So, an optimum charge density is required to balance the sinter bed permeability with sufficient heat transfer within the sinter bed.

$$
\text { Charge Density }=\frac{\text { Green mix tph } * 1080}{\text { Machine Speed } * 60 * \text { Bed Height } * \text { Machine Width }}
$$

The impact of charge density on internal return fines generation is shown in figure 4.

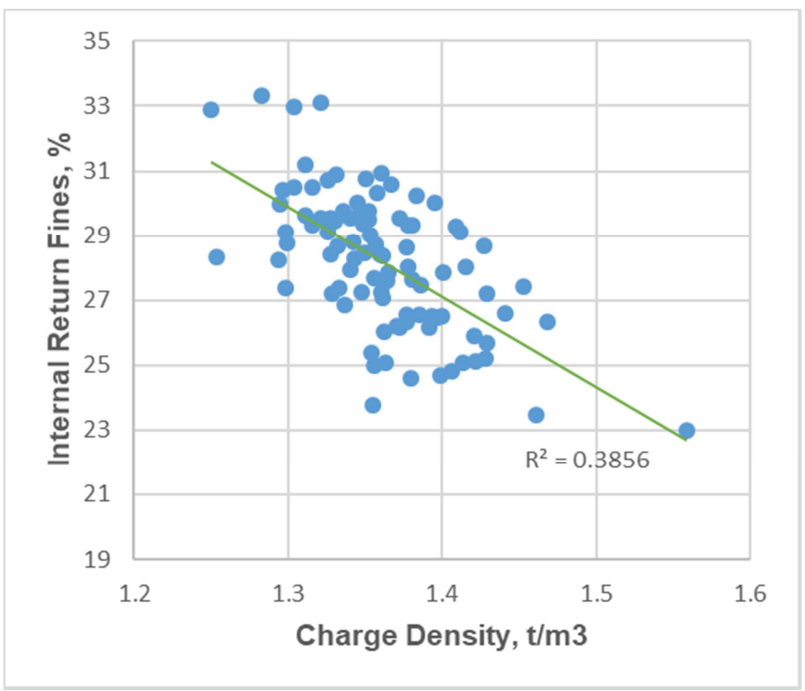

Figure 4. Impact of charge density.

\subsection{Effect of Sintering Rate}

As observed in table 3 , in addition to sinter basicity and charge density, sintering rate (measured by flame front speed and burn through length) also plays a key role in determining the internal return fines generation [15]. The plant operating regimes are classified based on the flame front speed, suction band and sinter basicity to arrive at an operating regime where internal return fines generation is optimized. At each sintering rate (flame front speed) levels, on-strand cooling rate or burn-through point length is targeted at the optimized value that reduces the internal return fines. The results of the analysis are as shown in table 4 . The table also shows that there is close significance between actual and predicted values as per the model.

Table 4. Internal Return Fines at Different Sintering Rates.

\begin{tabular}{|c|c|c|c|c|}
\hline $\begin{array}{l}\text { Sinter Basicity, } \\
\mathrm{CaO} / \mathrm{SiO}_{2}\end{array}$ & $\begin{array}{l}\text { Flame Front Speed, } \\
\mathrm{mm} / \mathrm{min}\end{array}$ & $\begin{array}{l}\text { Optimized Burn Through Point } \\
\text { Length, m }\end{array}$ & $\begin{array}{l}\text { Internal Return Fines\%, } \\
\text { Predicted }\end{array}$ & $\begin{array}{l}\text { Internal Return } \\
\text { Fines\%, Actual }\end{array}$ \\
\hline \multirow{3}{*}{1.7} & 18 & 111.2 & 25.9 & 25.4 \\
\hline & 21 & 111.2 & 26.1 & 26.3 \\
\hline & 24 & 110.0 & 26.3 & 26.7 \\
\hline \multirow[b]{2}{*}{1.85} & 18 & 111.8 & 25 & 24.6 \\
\hline & 21 & 111.2 & 25.3 & 24.8 \\
\hline \multirow{3}{*}{2} & 18 & 114.2 & 24.2 & 23.1 \\
\hline & 21 & 114.2 & 24.5 & 24.8 \\
\hline & 24 & 113.0 & 24.7 & 25.2 \\
\hline
\end{tabular}


generation, the process conditions were optimized to reduce the internal return fines generation by $2-3 \%$ (figure 5 ), given the constraint of sinter basicity and sintering rate as per the blast furnace requirement.

Prior to the development of the model, there was a lack of clarity on the process parameters that could be controlled to maintain the internal return fines generation in an acceptable band. The model could provide a fair prediction of the expected internal return fines generation and provide suggestions on operating band of controlling parameters. This enabled the operator to adjust the process parameters to reduce internal return fines generation in case of excess deviation.

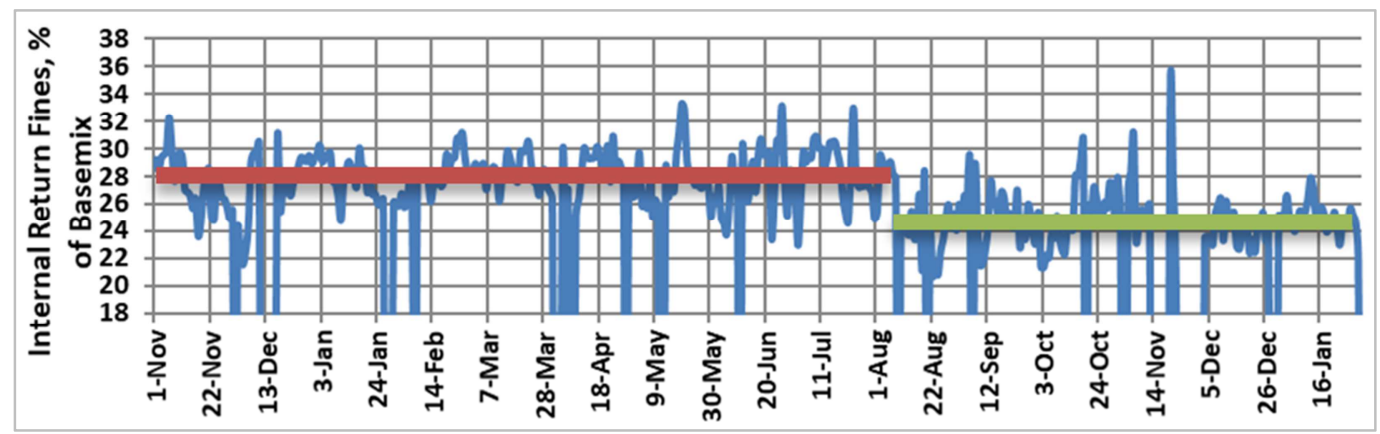

Figure 5. Internal Return Fines Generation at Tata Steel Kalinganagar.

\section{Conclusions}

Tata Steel Kalinganagar sinter plant had issues of high internal fines generation. However, limited literature was available on factors affecting internal return fines generation So, to better articulate the factors affecting the internal return fines generation, an extensive study starting from pile blending to sintering process parameters was pursued. Advanced analytic and statistical techniques have enabled us to identify key parameters affecting the internal return fines generation. Among the machine learning techniques, the Random Forest model prediction algorithm was found to have a good fit with actual values. The key parameters affecting the internal return fines generation were the sintering rate, sinter basicity, bed charge density and ignition hood temperature. In Kalinganagar, the increase in ignition hood temperature was limited by the ignition furnace refractory condition. Further, the sinter basicity is determined by the percentage of sinter in blast furnace burden, which limited drastic revisions in sinter basicity. Based on these operating regimes, the process parameters were optimized to generate the lowest possible return fines based on the model results. The understanding generated from machine learning has resulted in a drop in $2-3 \%$ in internal return fines generation. The machine learning modelling technique has many favorable features such as speed, optimization and simplicity, which makes it a useful choice for modeling complex systems. The model is further being developed to provide feedback on a real time basis to the operator using prescriptive analytics to enable real-time control.

\section{Acknowledgements}

We would like to acknowledge the entire sinter plant operation team of Tata Steel Kalinganagar, India, for extending their operational knowledge. We are also grateful to Tata Steel for permitting us to publish this work.

\section{Conflict of Interest}

The authors declare that they have no competing interests.

\section{References}

[1] Jesus Saiz and Maria Jose Posada, Non-linear State Estimator for Online Control of a Sinter Plant, ISIJ International, 53, 9, 1658-1664 (2013).

[2] Mróz Jan, Skowronek Ryszard and Francik Przemysław, Investigations on the Influence of Return Sinter Fines on the Iron Ores Sintering Process and on the Properties of Iron Ore Sinter, Proceedings of the 5th International Congress on the Science and Technology of Ironmaking, 2009.

[3] Ram Pravesh Bhagat, Factors Affecting Return Sinter Fines Regimes and Strand Productivity in Iron Ore Sintering, ISIJ International, 39, 9, 889-895 (1999).

[4] Kanjilal PP and Rose E, Application of adaptive prediction and control method for improved operation of the sintering process. Ironmaking and Steelmaking, 13, 289-293, 1986.

[5] Liu Song, Lyu Qing, Liu Xiaojie and Sun Yanquin, Synthetically predicting the quality index of sinter using machine learning model, Ironmaking and Steelmaking, 47, 7, 828-836 (2020).

[6] The perfect sinter plant control, Technical Document by Primetals.

[7] Shengli Wu, Juan Zhu, Jiaxin Fan, Guoliang Zhang and Shaoguo Chen, Sintering behavior of Return Fines and their effective utilization method, ISIJ International, 53, 9, 1561$1570,2013$.

[8] Himanshu Khandelwal, Shweta Srivastava, Adity Ganguly and Abhijit Roy, Prediction and Control of Coke Plant Wastewater Quality using Machine Learning Techniques, Coke and Chemistry, 63, 1, 47-56, 2020.

[9] Li-Heng Hsieh, Effect of Iron Ore Concentrate on Sintering Properties, ISIJ International, 57, 11, 1937-1946, 2017. 
[10] Satendra Kumar, Arvind Kumar Jaiswal, Rameshwar Sah, Marutiram Kaza, Manjini Sambandam and Prabhat Kumar Ghorui, An Innovative Approach for Utilization of Iron Ore Microfines (-150 microns) in Sintering, AISTech 2019, pp 495-499.

[11] Ziming Wang, Takayudi Maeda, Ko-ichiro Ohno and Kazuya Kunitomo, Effect of Magnetite on Mineral Phase Formation in Sintering Process, ISIJ International, 60, 2, 233-237, 2020.

[12] Chandra Shekhar Verma, Optimizing Sinter Chemistry to Counter Alumina Effect, AISTech 2019, pp 501 - 506.
[13] Hui Guo and Xing-Min Guo, Effect of Aluminum Occurrence State on the Formation of Calcium Ferrites in the Sintering Process of Iron Ore Fines, AISTech 2018, pp 595 - 606.

[14] M. Sinha, S. H. Nistala, S. Chandra, T. R. Mankhand and A. K. Ghose, Correlating mechanical properties of sinter phases with their chemistry and its effect on sinter quality, Ironmaking and Steelmaking, 44, 2, 100-107, 2017.

[15] C. E. Loo and R. D. Dukino, Laboratory iron ore sintering studies. 2 Quantifying flame front properties, Mineral Processing and Extractive Metallurgy, 123, 4, 197-203, 2014. 